\title{
Finnish Children Producing English Vowels - Studying in an English Immersion Class Affects Vowel Production
}

\author{
Katja Immonen \\ Department of Phonetics, Learning Age and Bilingualism Laboratory (LAB-lab), University of Turku, Finland \\ Maija S. Peltola \\ Department of Phonetics, Learning, Age and Bilingualism Laboratory (LAB-lab), University of Turku, Finland
}

\begin{abstract}
The aim of this study was to examine how earlier second language teaching affects Finnish school children's pronunciation of British English vowels. Two groups of Finnish children between the ages of eleven and thirteen were tested. The early learners studied in an English immersion class in a Finnish elementary school while the control group attended a regular Finnish speaking class at the same school. The task consisted of twenty three English stimulus words which included the twelve monophthong English target vowels in voiced and voiceless environments. The words were repeated seven times during the task. The participants produced the words after a native model and the target vowel qualities were then acoustically analysed. Statistical analysis revealed a group main effect. More specifically the analysis showed that the groups differed significantly in the way they produced target vowel second formant (F2) values. The F2 difference was only significant in the voiced context. Closer examination of the groups' vowel qualities revealed that the control group tended to produce the F2 values higher than the early learner group in most of the target vowels. The higher F2 values can be an indication of more frontal tongue position or less lip rounding during vowel production.
\end{abstract}

Index Terms - children, vowel production, second language learning

\section{INTRODUCTION}

When learning to produce a second language (L2) an individual can face various challenges depending on the similarities and differences between the sound systems of his or her mother tongue (L1) and the target language. According to second language learning theories, although completely new speech sounds are evidently challenging to learn, the most difficult L2 sounds to acquire are the ones which acoustically and motorically resemble L1 sounds. For example, the Speech Learning Model (SLM, (Flege, 1987; Flege, 1995)) and the Perceptual Assimilation Model (PAM, (Best, 1994)) state that L2 sounds that are similar to L1 sound categories are most likely to be assimilated to one or more L1 categories, thus causing maximal learning difficulties in the perception and production of L2 sounds. When an L2 sound is similar to an L1 category, the L2 sound is assimilated to, i.e. perceived as an exemplar of, an L1 sound category. This assimilation of L2 sounds causes the speaker to replace the difficult L2 sounds with similar L1 sounds, resulting in possible difficulties in communication. These difficulties continue until the speaker learns to perceive and thereafter produce the L2 contrasts that are irrelevant in his or her L1.

Although L2 learning poses different challenges to speakers of all ages, previous research has provided evidence that children are, in fact, often faster and more successful L2 learners than adults. For example, Giannakopoulou et al. (2013) discovered that Greek children (7-8 years) showed more improvement in English phoneme identification and discrimination than Greek adults (20-30 years) after high-variability perceptual training. This suggests an enhanced plasticity for L2 learning in childhood. Studies have also shown that children are particularly successful when they need to learn to accurately produce L2 sound qualities in language immersion situations (Oh et al., 2011; Tsukada et al., 2005). The study of Japanese immigrants in the United States by Oh et al. (2011) showed that Japanese adults produced English vowels more accurately than children when tested shortly after their arrival in the US, but after a year of immersion the child participants already produced English vowels with higher accuracy than adult subjects, suggesting them to be more efficient language learners. In addition, Tsukada et al. (2005) found that Korean children learning English as an L2 learned to produce the phonetic properties of English vowels more native-like than Korean adults, when compared to age-matched native English speakers. Furthermore, it has been shown that children can benefit even from very short term production training in laboratory conditions when learning to produce a difficult L2 vowel (Taimi, Jähi, Alku, \& Peltola, 2014). This finding indicates an ability to acquire difficult vowel contrasts efficiently through simple listen and repeat training even in unnatural learning settings.

Research has also provided evidence that early age of acquisition (AOA) correlates with more native-like L2 vowel production accuracy in early and late bilinguals (Piske, Flege, MacKay, \& Meador, 2002). However, AOA is not the 
only factor that affects L2 learning and pronunciation. For instance, it has been shown that the effect of the amount of L1 use on the degree of perceived foreign accent in L2 speech can in fact be stronger than the effect of AOA (Flege, Frieda, \& Nozawa, 1997). This study compared two groups of early Italian-English bilinguals who immigrated to Canada as young children. The group who reported using Italian often was judged by native English speakers to have significantly stronger foreign accent in their L2 than the group who spoke Italian rarely. Taken together these results suggest children to be highly efficient and successful L2 learners, who can modify their pronunciation according to L2 phonetic information extracted from natural language exposure situations or from more explicit training situations.

Finnish children start school at the age of 7 and continue in elementary school for six years until the age of 13. Most children begin their first foreign language studies on the third grade at the age of 9. The first L2 for Finnish school children is usually English and it is taught for two to three hours per week. This means that by the end of elementary school, most Finnish children have studied English for three years. However, there are separate immersion language classes where L2 learning begins already on the first grade, so that all teaching is given in English or another L2. Therefore, children can have vastly different amounts of English experience at the end of elementary school. The Finnish National Agency for Education has implemented a reformation of the national core curricula which prepones English teaching to the first grade. In other words, children can start their English studies at the age of 7 as soon as they enter elementary school or later at the ages of 8 to 9 on the second or third grades. In the reformed national curricula English lessons are distributed evenly throughout elementary school, so that the overall amount of English teaching stays the same regardless of when children begin their L2 studies. Research on the sensitive period of language learning (Johnson \& Newport, 1989) supports the idea of earlier L2 teaching, but there is not much research on how different language learning environments or immersion programs in school affect the development of L2 pronunciation. Some studies have focused on the effects of language immersion day care on L2 category perception and discrimination (Peltola, Kuntola, Tamminen, Hämäläinen, \& Aaltonen, 2005; Peltola, Tuomainen, Koskinen, \& Aaltonen, 2007). In these studies it was found that early L2 exposure in immersion day care might or might not alter the children's L2 perception. However, these experiments only focused on the perception of L2 sound categories and excluded the production aspect of L2 learning. Therefore, the question of how immersion classes and earlier L2 teaching affect the pronunciation accuracy of L2 sounds remains unsolved.

The aim of this study was to examine how earlier L2 teaching in an immersion language class affects Finnish children's pronunciation of British English vowels. The Finnish phonological vowel system contains eight vowels: /a/,/e/, /i/, /o/, /u/, /y/, /æ/and /ø/ (Suomi, Toivanen, \& Ylitalo, 2008). British English Received Pronunciation (RP),

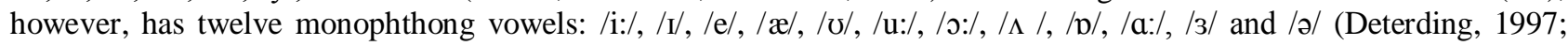
Roach, 2004). Therefore, in the light of L2 learning models and theories, it can be hypothesized that Finnish speakers face difficulties when learning English vowels, since they have to learn to perceive and produce phonological contrasts that are irrelevant in their L1. British English vowels are theoretically maximally difficult for Finnish children to learn, since vowels can never be perceived by an L2 learner as completely new sounds, meaning they are initially always assimilated to L1 vowel categories (Peltola, 2003). It can be hypothesized that in the present study, the vowels /I/, / $/$, $/ \mathrm{s} /, / \Lambda /, / \mathrm{D} /, / 3 /$ and $/ \mathrm{\partial} /$ of the twelve tested British English monophthong sounds would theoretically be the most difficult for Finnish children to produce, as these categories are phonologically irrelevant in Finnish and are likely to be assimilated to L1 vowel categories. Children who have studied in an English immersion class, however, may have benefited from the daily English exposure in school and might not encounter equal difficulties in the production of these theoretically difficult vowels as the children who have only studied English for three years as a separate school subject.

\section{MATERIAL AND METHODS}

\section{A. Participants}

The 32 participants in this study were 11-13-year-old Finnish school children who were on their last year of elementary school. The early learner group consisted of 17 participants (10 girls, aged 12;4-13;2, median 12;9), who all attended an English immersion class, where all school subjects were taught in British English. Most of the participants had attended the immersion class throughout elementary school (6 years). One participant had studied in the English speaking class for only 2 years and had lived in Australia for 3 years. Another participant had attended the immersion class for 3 years but had lived in the United States for 3,5 years. One participant had lived in the United States for 2 years before starting school and had attended the English speaking class for full 6 years. Almost all of the children in the early learner group had some contact with English outside school - two had attended an English immersion day care and many others had English speaking relatives or acquaintances. However, none of the children spoke English at home or had English speaking parents and none of them spoke English as an L1.

The participants in the control group were 17 children from a Finnish speaking class ( 8 girls, aged 11;9-12;7, median $12 ; 2$ ) from the same school. They had studied English since the third grade (3 years) as a separate school subject for 2-3 hours per week, according to the Finnish National Agency for Education's national core curricula. One participant had lived in Norway for a year and one reported speaking Arabic at home with family members. Two participants from the control group were excluded from data analyses because the language background questionnaire revealed them to be Finnish-English bilinguals - both had one English and one Finnish speaking parent and they had learned English from 
birth. Thus data from 17 participants in the early learner group and 15 participants from the control group were included in the analyses. The participants' language backgrounds were not strictly controlled because the aim was to test two representative groups of Finnish school children from an average Finnish school.

All participants and their parents gave a written informed consent before the experiment and the study was conducted with permission from the Ethics Committee of the University of Turku.

\section{B. Stimuli}

The stimuli were 23 English words containing the 12 target British English monophthong vowels /i:/, /I/, /e/, /æ/, / /, $/ \mathrm{u}: /, / \mathrm{o} / /, / \Lambda /, / \mathrm{p} /, / \mathrm{a}: /, / 3 /$ and /ə/. Each of the vowels, excluding the neutral central vowel /ə/, appeared in a fortis and lenis context in the selected stimulus words, i.e. before voiceless and voiced consonants. The stimulus words containing the target vowels are listed in Table 1.

TABLE I

STIMULUS WORDS

\begin{tabular}{|c|c|c|c|c|c|c|c|c|c|c|c|c|}
\hline & /i:/ & $/ \mathrm{I} /$ & /e/ & $/ \mathfrak{a} /$ & $/ \delta /$ & /u:/ & /o:/ & $/ \mathbf{L} /$ & $/ \mathrm{p} /$ & /a:/ & /3:/ & /а/ \\
\hline \multirow[t]{2}{*}{ Voiceless } & heat & hit & bet & hat & foot & hoot & bought & hut & tot & heart & hurt & \\
\hline & /hi:t/ & /hit/ & /bet/ & /hæt/ & /fut/ & /hu:t/ & /bo:t/ & $/ \mathrm{h} \wedge \mathrm{t} /$ & /tpt/ & /ha:t/ & /h3:t/ & \\
\hline \multirow[t]{2}{*}{ Voiced } & heed & hid & bed & had & hood & who'd & board & hud & Todd & hard & heard & harder \\
\hline & /hi:d/ & /hid/ & /bed/ & /hæd/ & /hod/ & /hu:d/ & /bo:d/ & $/ \mathrm{h} \Lambda \mathrm{d} /$ & /tod/ & /ha:d/ & /h3:d/ & /ha:də/ \\
\hline
\end{tabular}

The stimuli were recorded from a native British English speaker (male) in an earlier study (Peltola, Lintunen, \& Tamminen, 2014). The speaker produced each word seven times, 161 tokens in total. The recording paradigm included all seven repetitions of the 23 stimulus words in order to maintain natural variance in the stimuli and the target vowel qualities.

\section{Procedure}

The procedure was a simple listen and repeat task where the participants were instructed to listen closely to the English words that they heard and then repeat them aloud. The data was collected using a PC laptop computer running Sanako Student Recorder software (version 7.20) and a Beyerdynamic MMX300 headset connected to an Asus Xonar U3 soundcard. The experiment was conducted during school hours in the school library. No written prompt of the stimulus words was given during the task to avoid any orthographical interference in the productions. The 161 stimulus words were presented in a pseudorandomized order with an inter-stimulus interval (ISI) of 3000ms. There were two self-paced breaks during the task. The experiment lasted for 10-12 minutes in total, depending on the length of the breaks.

\section{Analysis}

All productions were acoustically analysed using Praat speech analysing software (version 5.3.01). The first (F1) and second formants (F2) as well as the fundamental frequency (F0) were extracted from the steady state phase of the target vowels, where the formants were not in transition and the vowel quality was stable. The formant values were measured from all seven repetitions of the stimuli (161 tokens per subject) and average target vowel formant values were then calculated for each subject. In addition, vowel durations were measured from the beginning of voicing or explosion to the start of occlusion at the beginning of the word final consonant. However, no further analysis was conducted on the duration data as the focus of the study was on vowel quality.

The vowel /ə/ was excluded from statistical analysis, since the word final position of the vowel resulted in creaky voice and poor quality in most of the productions, and therefore no formant frequency values for /ə/ could be extracted from much of the data. The F1 and F2 values for each of the remaining 11 target vowels from both groups were statistically analysed using IBM SPSS Statistics software (version 22). A repeated measures analysis of variance (ANOVA) was conducted first for both groups and the analysis continued with further tests for statistically relevant interactions. Only significant findings are reported.

\section{Results}

The formant frequency data was analysed using a Group (2) x Vowel (11) x Voice (2) x Measure (2) repeated measures ANOVA, which revealed a significant main effect of Group, indicating a difference between the early learners and the control group $(\mathrm{f}(10,21)=2.715, \mathrm{p}=0.026)$. The analysis also revealed a Group (2) $\mathrm{x}$ Vowel $(11) \mathrm{x}$ Measure (2) interaction, meaning that the groups used F1 and F2 values differently in different vowels $(\mathrm{f}(10,21)=2,399$, $\mathrm{p}=0.044$ ). A Group (2) x Vowel (11) x Measure (2) analysis for the voiced and voiceless words revealed that the difference between groups was significantly larger in the voiced context, i.e. in the words where the vowel was followed by a voiced consonant $(\mathrm{f}(10,21)=2,611, \mathrm{p}=0.031)$. A Group (2) x Vowel (11) analysis also revealed that, more specifically, the significant difference was produced in the $F 2$ values $(f(10,21)=3,191, p=0.012)$. In other words, the two groups used the F2 values differently in the production of the target vowels. The F2 difference was valid for the words with a voiced consonant context $(\mathrm{f}(10,21)=3,056, \mathrm{p}=0.015)$. 
The average formant values for each vowel from both groups and the stimuli produced by a native male speaker are listed in Table 2. A closer examination of the formant values revealed that the control group tended to produce the British English vowels with higher F2 values than the early learners, which might suggest a more frontal tongue position or less lip rounding during the production of these vowels. The control group produced higher F2 values especially in the vowels /I/, / / and / $/$ / but the formant values seem to differ largest in /I/ in the word hid (Early learners: F2= $2587 \mathrm{~Hz}$, Control group: F2= $2712 \mathrm{~Hz}$ ) where the absolute difference between groups is $125 \mathrm{~Hz}$. These findings explain the statistical Group (2) x Vowel (11) interaction. In addition, the formant values also reveal that the control group produced the vowels /u:/ and /3:/ with lower F2 values than the early learners, which could be an indication of either a more backed tongue position or a more rounded lip position during articulation. The average formant values of the stimuli produced by a native British English speaker differed from both subject groups' F1 and F2 values. This was to be expected, as the fundamental frequency in 11 to 13 year-old children is considerably higher than the pitch of an adult male speaker due to physiological reasons, resulting in higher F1 and F2 frequencies in the vowels produced by the children.

TABLE II.

TARGET VOWEL FORMANT VALUES

\begin{tabular}{|c|c|c|c|c|c|}
\hline Vowel & Context & Formant & Native & Early learners & Control group \\
\hline \multirow{4}{*}{ /i:/ } & \multirow{2}{*}{ /hi:t/ } & $\mathrm{F} 1$ & 269 & 398 & 428 \\
\hline & & F2 & 2334 & 2773 & 2831 \\
\hline & \multirow[t]{2}{*}{ /hi:d/ } & F1 & 269 & 397 & 418 \\
\hline & & $\mathrm{F} 2$ & 2311 & 2749 & 2827 \\
\hline \multirow[t]{4}{*}{$/ \mathrm{I} /$} & \multirow[t]{2}{*}{ /hit/ } & F1 & 378 & 457 & 454 \\
\hline & & F2 & 2160 & 2572 & 2706 \\
\hline & \multirow[t]{2}{*}{ /hId/ } & F1 & 333 & 443 & 449 \\
\hline & & $\mathrm{F} 2$ & 2204 & 2587 & 2712 \\
\hline \multirow[t]{4}{*}{ /e/ } & \multirow[t]{2}{*}{ /bet/ } & F1 & 613 & 621 & 632 \\
\hline & & F2 & 1916 & 2134 & 2230 \\
\hline & \multirow[t]{2}{*}{ /bed/ } & F1 & 502 & 623 & 624 \\
\hline & & $\mathrm{F} 2$ & 1964 & 2171 & 2228 \\
\hline \multirow[t]{4}{*}{$/ \mathfrak{a} /$} & \multirow[t]{2}{*}{ /hæt/ } & F1 & 950 & 897 & 915 \\
\hline & & F2 & 1577 & 1826 & 1908 \\
\hline & \multirow[t]{2}{*}{ /hæd/ } & F1 & 884 & 872 & 880 \\
\hline & & F2 & 1511 & 1833 & 1890 \\
\hline \multirow[t]{4}{*}{$/ 0 /$} & \multirow[t]{2}{*}{ /fut/ } & F1 & 411 & 478 & 468 \\
\hline & & F2 & 857 & 1299 & 1262 \\
\hline & \multirow[t]{2}{*}{ /hod/ } & $\mathrm{F} 1$ & 351 & 454 & 449 \\
\hline & & F2 & 967 & 1180 & 1220 \\
\hline \multirow[t]{4}{*}{ /u:/ } & \multirow[t]{2}{*}{ /hu:t/ } & F1 & 280 & 432 & 444 \\
\hline & & F2 & 1398 & 1415 & 1404 \\
\hline & \multirow[t]{2}{*}{ /hu:d/ } & F1 & 272 & 422 & 428 \\
\hline & & F2 & 1256 & 1358 & 1272 \\
\hline \multirow[t]{4}{*}{ /o:/ } & \multirow[t]{2}{*}{ /bo:t/ } & F1 & 403 & 515 & 548 \\
\hline & & F2 & 678 & 1005 & 1087 \\
\hline & \multirow[t]{2}{*}{ /bo:d/ } & F1 & 381 & 504 & 552 \\
\hline & & F2 & 604 & 967 & 1029 \\
\hline \multirow[t]{4}{*}{$/ \mathbf{N} /$} & \multirow[t]{2}{*}{$/ \mathrm{h} \Lambda \mathrm{t} /$} & F1 & 721 & 766 & 789 \\
\hline & & F2 & 1079 & 1383 & 1433 \\
\hline & \multirow[t]{2}{*}{$/ \mathrm{h} \Lambda \mathrm{d} /$} & F1 & 728 & 724 & 766 \\
\hline & & F2 & 1114 & 1459 & 1483 \\
\hline & $/ \mathrm{tpt} /$ & $\mathrm{F} 1$ & 590 & 584 & 623 \\
\hline$/ \mathbf{p} /$ & & F2 & 1134 & 1188 & 1285 \\
\hline & /tpd:/ & F1 & 507 & 579 & 614 \\
\hline & & F2 & 856 & 1194 & 1271 \\
\hline /a:/ & /ha:t/ & F1 & 651 & 720 & 751 \\
\hline & & F2 & 985 & 1229 & 1259 \\
\hline & /ha:d/ & F1 & 632 & 694 & 720 \\
\hline & & F2 & 968 & 1214 & 1230 \\
\hline /3:/ & /h3:t/ & F1 & 491 & 605 & 655 \\
\hline & & F2 & 1415 & 1823 & 1785 \\
\hline & /h3:d/ & F1 & 461 & 580 & 620 \\
\hline & & $\mathrm{F} 2$ & 1480 & 1824 & 1774 \\
\hline
\end{tabular}

The average target vowel F1 and F2 values (Hz) from seven repetitions of the test words from both subject groups and the native British English speaker who produced the stimulus words.

\section{DISCUSSION}

The results show that the two groups tested in this study produced the eleven British English monophthong vowels differently. This is in accordance with the initial research hypothesis that the daily exposure to British English might be 
reflected in the early learners' vowel productions even when compared to children who had studied English for three years in a classroom setting. The two groups used second formant values differently in the production of the target vowel qualities and the difference in F2 values was statistically significant. This finding supports the notion that age of acquisition and the manner of learning affect the attainment of L2 pronunciation. The results of this study suggest that the children who had started learning English at a younger age in an immersion style setting in an English speaking class had benefitted from the earlier and more extensive L2 exposure, which was reflected in their English vowel productions. Most of the children in the early learner group had been exposed to English from the age of 7 for six years and they had studied all school subjects in English during their time in the immersion class. The participants in the control group, however, had only studied English for three years as a separate school subject after beginning their L2 studies at the age of 9. Therefore the early learners had an average of three years more L2 experience and they had started acquiring the language at a younger age than the control group. In addition, the early learners had had more English exposure and input throughout elementary school, since they studied all their subjects in English. The control group, on the other hand, only studied English for 2 to 3 hours a week as a separate subject while all other subjects were taught in Finnish.

Statistical analysis revealed that the difference in the groups' F2 values was significant in the voiced but not in the voiceless stimulus words. There is no definite explanation for this finding, but there are a couple of possibilities that might explain the difference. Firstly, we have to consider the phonology and phonotactic rules of the Finnish language which greatly differ from those of English. Theoretically, the voiced stop consonant /d/ is phonological in Finnish. However, it is practically always realised as voiceless / $t /$ in regular speech. In addition, a voiced stop consonant can never appear in a word final position in Finnish, as a word can only end in a vowel or the consonants /t/, /n/, /s/, /l/ or /r/ (Suomi et al., 2008). Therefore, the voiced stimulus words used in this study ending in /d/ were probably particularly challenging for the control group from an articulatory point of view, as they were not used to producing a voiced stop consonant in a word final position. On the other hand, the early learners who had had more English experience, could better perceive and focus on the production of the target vowels as the production of voicing in the word final consonant did not require as much effort.

Another explanation could simply be that the vowel quality difference between groups was more easily measurable in the voiced target words due to the pre-lenis lengthening phenomenon found in British English phonology. Pre-lenis lengthening and pre-fortis clipping affect sound duration in the vowel preceding a consonant. When a vowel is followed by a voiced consonant, such as /d/, the vowel is produced slightly longer than before a voiceless consonant such as / $\mathrm{t} /$. Therefore, it might be that the steady states of the target vowel formants were more stable in the words with voiced consonant context and this could have been reflected in the formant measurements. However, the duration of the target vowels in pre-lenis and pre-fortis environments was not analysed due to technical difficulties in obtaining the duration data from the recordings, and therefore no further conclusions of the effects of vowel duration on vowel quality can be drawn from this data.

Closer inspection of the formant values listed in Table 2 revealed that the groups' production of F1 and F2 frequencies in the target vowels differed especially in four of the vowels that are not phonological in Finnish $(/ \mathrm{I} /, / \mathrm{p} /, / \mathrm{\rho} /$ and /3/), i.e. vowels which are similar to Finnish vowels and were hypothesized to cause most differences between the two groups. This finding is congruent with the theoretical framework of second language learning and supports the prediction that L2 sounds that are similar, but not identical, to L1 categories are most challenging to learn. For example, the formant values for each target vowel in Table 2 revealed that the participants in the control group produced the vowel /I/ with considerably higher F2 values than the early learners. In fact, the F2 values for the English vowel /I/ in the words hit and hid are very close to the F2 values in the vowel /i:/ in the words heat and heed. This finding is in accordance with second language learning theories and models (Best, 1994; Flege, 1995; Kuhl, Williams, \& et al, 1992) as well as previous research findings (Peltola et al., 2003; Peltola et al., 2014), which predict that the lax vowel /I/ is one of the most difficult English sounds for Finnish L1 speakers to learn. Peltola et al. (2014) showed that university English students produced English vowels in a more native-like manner after explicit pronunciation teaching and the learning effect was best reflected in /I/. A study by Ylinen et al. (2010) has also provided evidence that native Finnish speakers tend to use duration cues rather than spectral cues in the discrimination of the English /i:/ - /I/ contrast, which can also be expected to be reflected in the production of these vowels. Looking at the results of the present study, it seems that the control group assimilated the English lax /I/ to Finnish /i/ category and produced it as more frontal than the early learners, resulting in higher F2 values.

The formant values listed in Table 2 reveal that the control group did produce slightly lower F2 values for /I/ than /i:/, but the difference between the vowels is not as clear as the difference produced by the early learners. This might indicate that the children who did not study in the English immersion class had more difficulties producing the two similar vowels as separate sounds, since they both were assimilated to Finnish /i/ sound category. The early learners, however, probably benefited from more extensive English experience and were therefore able to distinguish these two vowels better in their productions. These differences in the pronunciation of the vowel /I/ most likely explain the Group (2) $x$ Vowel (11) x Measure (2) interaction found in the statistical analysis.

All in all, the results of this study support the hypothesis that the L2 experience of the early learners from the English immersion class was reflected in their pronunciation, as their production of British English vowels differed significantly 
from the vowels produced by the control group enrolled in a Finnish speaking class. Both the manner of learning and the age of acquisition explain the difference between the groups. In order to reliably draw conclusions of the pronunciation accuracy of the two groups, their productions should be compared to a third group of age-matched native British English speakers, which regrettably was not possible in the scope of the present study. However, it can be said that there is a significant difference in the way Finnish children from a Finnish speaking class and an English speaking class produce British English vowels and this difference can be explained by the differences in age of acquisition as well as English language experience and amount of exposure. This result supports the preponing of English teaching to the first grade, as guided by the new national core curricula from the Finnish National Agency for Education. Although the two groups tested in this study differed both in terms of age of acquisition and in manner of learning, the result gives reason to assume that children could benefit from earlier L2 teaching in terms of pronunciation even if it was provided only in separate L2 lessons.

\section{ACKNOWLEDGMENTS}

The authors wish to thank Elina Lehtilä, BA, for her help in analysing this data. We also wish to thank Sanako Corp. for sponsoring the LAB-laboratory. We would also wish to thank the children who participated in this study and their parents for co-operation. The first author is financed by doctoral program Utuling of University of Turku.

\section{REFERENCES}

[1] Best, C. T. (1994). The emergence of native-language phonological influences in infants: A perceptual assimilation model. In J. C. Goodman \& H. C. Nusbaum (eds.), The Development of Speech Perception: The Transition from Speech Sounds to Spoken Words. Cambridge, MA: MIT Press, 167-224.

[2] Deterding, D. (1997). The formants of monophthong vowels in standard southern British English pronunciation. Journal of the International Phonetic Association 27.1-2, 47-55.

[3] Flege, J. E. (1987). The production of "new" and "similar" phones in a foreign language: Evidence for the effect of equivalence classification. Journal of Phonetics 15, 47-65.

[4] Flege, J. E. (1995). Second language speech learning: Theory, findings, and problems. In W. Strange (ed.), Speech Perception and Linguistic Experience: Issues in Cross-Language Research. Timonium, MD: York, 229-273.

[5] Flege, J. E., Frieda, E. M., \& Nozawa, T. (1997). Amount of native-language (L1) use affects the pronunciation of an L2. Journal of Phonetics 25.2, 169-186.

[6] Giannakopoulou, A., Uther, M., \& Ylinen, S. (2013). Enhanced plasticity in spoken language acquisition for child learners: Evidence from phonetic training studies in child and adult learners of English. Child Language Teaching and Therapy 29.2, 201-218.

[7] Johnson, J. S., \& Newport, E. L. (1989). Critical period effects in second language learning: The influence of maturational state on the acquisition of English as a second language. Cognitive Psychology 21.1, 60-99. doi: http://dx.doi.org/10.1016/00100285(89)90003-0

[8] Kuhl, P. K., Williams, K. A., \& et al. (1992). Linguistic experience alters phonetic perception in infants by 6 months of age. Science 255.5044, 606-608.

[9] Oh, G. E., Guion-Anderson, S., Aoyama, K., Flege, J. E., Akahane-Yamada, R., \& Yamada, T. (2011). A one-year longitudinal study of English and Japanese vowel production by Japanese adults and children in an English-speaking setting. Journal of Phonetics 39.2, 156-167.

[10] Peltola, M. S., Kujala, T., Tuomainen, J., Ek, M., Aaltonen, O., \& Näätänen, R. (2003). Native and foreign vowel discrimination as indexed by the mismatch negativity (MMN) response. Neuroscience Letters 352.1, 25-28.

[11] Peltola, M. S., Kuntola, M., Tamminen, H., Hämäläinen, H., \& Aaltonen, O. (2005). Early exposure to non-native language alters preattentive vowel discrimination. Neuroscience Letters 388.3, 121-125.

[12] Peltola, M. S., Lintunen, P., \& Tamminen, H. (2014). Advanced English learners benefit from explicit pronunciation teaching: An experiment with vowel duration and quality. AFinLA-E: Soveltavan Kielitieteen Tutkimuksia 6, 86-98.

[13] Peltola, M. S., Tuomainen, O., Koskinen, M., \& Aaltonen, O. (2007). The effect of language immersion education on the preattentive perception of native and non-native vowel contrasts. Journal of Psycholinguistic Research 36.1, 15-23.

[14] Peltola, M. S. (2003). The attentive and preattentive perception of native and non-native vowels: The effect of second language learning. Turku: University of Turku, Department of Phonetics.

[15] Piske, T., Flege, J. E., MacKay, I. R., \& Meador, D. (2002). The production of English vowels by fluent early and late ItalianEnglish bilinguals. Phonetica 59.1, 49-71. doi:56205 [pii]

[16] Roach, P. (2004). British English: Received pronunciation. Journal of the International Phonetic Association 34.02, $239-245$.

[17] Suomi, K., Toivanen, J., \& Ylitalo, R. (2008). Finnish sound structure: Phonetics, phonology, phonotactics and prosody. Oulu: Oulu University Press.

[18] Taimi, L., Jähi, K., Alku, P., \& Peltola, M. S. (2014). Children learning a non-native vowel - The effect of a two-day production training. Journal of Language Teaching and Research 5.6, 1229-1235.

[19] Tsukada, K., Birdsong, D., Bialystok, E., Mack, M., Sung, H., \& Flege, J. (2005). A developmental study of English vowel production and perception by native Korean adults and children. Journal of Phonetics 33.3, 263-290.

[20] Ylinen, S., Uther, M., Latvala, A., Vepsäläinen, S., Iverson, P., Akahane-Yamada, R., \& Näätänen, R. (2010). Training the brain to weight speech cues differently: A study of Finnish second-language users of English. Journal of Cognitive Neuroscience 22.6, 1319-1332. 
Katja Immonen, MA, is a $\mathrm{PhD}$ candidate from the Department of Phonetics and Learning, Age and Bilingualism Laboratory (LAB-lab), University of Turku, Finland. Her main research is focused on the effect of different language learning backgrounds on children's second language learning. Her research interests also include children's second language perception and production.

Maija S. Peltola, PhD, is an Associate Professor and the head of the Department of Phonetics and Learning, Age and Bilingualism -laboratory at the University of Turku, Finland. Her research interests include a wide range of topics related to the perceptual and productional acquisition of non-native speech. 